Revista Brasileira de

Engenharia Agrícola e Ambiental

v.13, n.4, p.411-418, 2009

Campina Grande, PB, UAEA/UFCG - http://www.agriambi.com.br

Protocolo 191.07 - 05/12/2007 • Aprovado em 15/12/2008

\title{
Culturas de cobertura e qualidade física de um Latossolo em plantio direto
}

\author{
$\overline{\text { Rui da S. Andrade1, Luís F. Stone }{ }^{2} \& \text { Pedro M. da Silveira }}{ }^{2}$
}

\section{RESUMO}

Com este trabalho se objetivou determinar o efeito de culturas de cobertura na qualidade física de um Latossolo Vermelho distrófico em plantio direto. 0 experimento foi irrigado por pivô central e conduzido na Embrapa Arroz e Feijão, em Santo Antônio de Goiás, GO, no delineamento de blocos ao acaso, com oito repetições. Os tratamentos consistiram de oito culturas de cobertura: braquiária; milho consorciado com braquiária; guandu anão; milheto; mombaça; sorgo; estilosantes e crotalária. As sete primeiras vêm sendo cultivadas no verão desde dezembro de 2001 e a crotalária a partir de novembro de 2003. No inverno de cada ano e após dessecação dessas culturas, foi implantado o feijoeiro irrigado e, em fevereiro de 2006, determinados 0 conteúdo de matéria orgânica do solo, alguns atributos físicos e sua qualidade física, por meio do índice $S$. As culturas de cobertura, especialmente as gramíneas, favoreceram a agregação do solo na camada superficial. 0 cultivo do solo modificou a sua estrutura comparativamente à mata nativa, aumentando sua densidade e reduzindo a macroporosidade, porosidade total e qualidade física. Entre as culturas de cobertura guandu, crotalária e milho consorciado com braquiária, foram as que mantiveram a camada superficial do solo com boa qualidade física.

Palavras-chave: Phaseolus vulgaris, atributos físicos, índice S, pivô central, cerrado

\section{Cover crops and physical quality of a Latosol under no-tillage}

\begin{abstract}
The objective of this study was to determine the effect of cover crop mulches on the physical quality of a distrophic Red Latosol (0 xisol) under no-tillage. The experiment was carried out under center pivot at Embrapa Rice \& Beans, in Santo Antônio de Goiás, GO, in a randomized block design, with eight replications. The treatments consisted of eight cover crops: Brachiaria brizantha; com associated with B. brizantha; pigeon pea; millet; Panicum maximum; sorghum; Stylosanthes guianensis; and Crotalaria juncea. The first seven crops had been cultivated in summer season since December 2001 and C. juncea since N ovember 2003. In the winter season, after cover crop desiccation, irrigated common bean crop under no-illage was planted. In February 2006, soil organic matter content, some soil physical attributes, and soil physical quality measured by Sindex were determined. Cover crops, especially grasses, favored soil aggregation at the surface layer. Soil cultivation modified its structure in comparison to native forest, increasing bulk density and reducing macroporosity, total porosity, and soil physical quality. Among the cover crops, pigeon pea, C. juncea, and corn associated with B. brizantha were those that maintained soil surface layer with good physical quality.
\end{abstract}

Key words: Phaseolus vulgaris, physical attributes, S index, center pivot, cerrado

\footnotetext{
1 Departamento de Hidráulica/UFT, CEP 77020-120, Palmas, TO. Fone (63) 3232-8021, (63) 9201-3210. E-mail: andradersilva@uft.edu.br

${ }^{2}$ Embrapa Arroz e Feijão, CP 179, CEP 75375-000, Santo Antônio de Goiás, GO. Fone (62) 3533-2151. E-mail: stone@cnpaf.embrapa.br; pmarques@cnpaf.embrapa.br
} 


\section{INTRODUÇÃO}

A adoção de sistemas de rotação de culturas, em especial no sistema plantio direto (SPD), tem sido preconizada para o manejo físico, químico e biológico do solo. Do ponto de vista da física do solo, tem-se estimulado a adoção da rotação de culturas para manter e/ou aumentar os teores de matéria orgânica, criar poros biológicos, melhorar a estrutura e manter palha suficiente na superfície do solo. A bioporosidade criada pela atividade radicular e mesofauna do solo e a possibilidade das raízes de algumas culturas penetrarem camadas mais compactadas, têm sido o motivo de se considerar a rotação de culturas fundamental em plantio direto. Estratégias de manejo que mantêm ou adicionam carbono ao solo, têm bom potencial para a melhoria da qualidade física do solo para o crescimento das plantas.

O acúmulo de material orgânico no SPD tem origem na inexistência de revolvimento do solo, que resulta em menores taxas de decomposição do material orgânico e em menores perdas por erosão. O material vegetal adicionado superficialmente, decompõe mais lentamente quando não é incorporado, porque fica menos exposto aos microrganismos do solo. A matéria orgânica do solo também fica menos exposta ao ataque dos microrganismos pois, sem o revolvimento, não há quebra das estruturas que a protegem fisicamente dos agentes decompositores; assim, vários autores têm registrado aumentos nos teores de matéria orgânica da camada superficial de solos em plantio direto (Bayer \& Mielniczuk, 1997; Corazza et al., 1999; Amado et al., 2001).

Além do enriquecimento de matéria orgânica do solo, o SPD permite o acúmulo de resíduos vegetais na superfície do solo. A baixa densidade dos resíduos orgânicos, deixados sobre a superfície do solo, também pode resultar em atenuação das cargas aplicadas sobre o mesmo; desta forma, Dao (1996) observou que a remoção dos resíduos vegetais da superfície do solo resultou em aumentos na densidade do solo, especialmente na camada entre 5 e 12,5 $\mathrm{cm}$ de profundidade no sistema de cultivo convencional e entre 0 e $5 \mathrm{~cm}$ no plantio direto. $\mathrm{O}$ autor conclui, ainda, que a manutenção de grandes quantidades de resíduos vegetais na superfície do solo contribuiu para maior macroporosidade na camada superficial em solos sob cultivos conservacionistas.

A quantidade de material vegetal adicionado na superfície e a quantidade de matéria orgânica acumulada no solo, são dependentes do sistema de culturas adotado (Bayer et al., 2000; Amado et al., 2001). Aqueles sistemas que incluem culturas com alta produção de matéria seca e culturas com baixa relação $\mathrm{C} / \mathrm{N}$ resultam, em geral, em maiores acúmulos de matéria orgânica no solo.

Os resíduos de leguminosas têm grande importância como fornecedores de $\mathrm{N}$, podendo contribuir para a diminuição da acidez do solo e da relação $\mathrm{C} / \mathrm{N}$ da matéria orgânica do solo (Hargrove, 1986). Em contrapartida, os resíduos das gramíneas promovem a melhoria do solo, por possuírem maior conteúdo de lignina, possibilitando aumento de ácidos carboxílicos e ácidos húmicos nos substratos (Primavesi, 1982), favorecendo a estruturação e a estabilidade dos agregados do solo (Fassbender \& Bornemisza, 1994), tornando-o menos suscetível à compactação.

Sistemas com rotação ou sucessão de culturas podem ter variações na agregação do solo, de acordo com as diferenças nas espécies de plantas. A diferença entre espécies pode estar na qualidade do material orgânico sintetizado pelas raízes das diversas culturas ou na configuração das raízes, especialmente na proporção das raízes laterais (Wohlenberg et al., 2004), uma vez que a liberação da matéria orgânica ocorre segundo o tipo de raiz (Reid \& Goss, 1982). A estabilidade de agregados sob leguminosas pode ser maior em relação às nãoleguminosas, pois há maior massa microbiana para o mesmo comprimento e massa de raízes, além de maior comprimento de hifas de fungos nas leguminosas, em relação às não-leguminosas (Haynes \& Beare, 1997).

Campos et al. (1999) e Wohlenberg et al. (2004) verificaram que a seqüência de culturas com a sucessão de gramíneas com leguminosas favoreceu a maior agregação do solo. Os primeiros autores atribuíram este comportamento ao sistema radicular da gramínea e à taxa de decomposição da leguminosa, criando ambiente favorável à agregação pela ação das raízes, cobertura do solo, fornecimento de material orgânico e conservação da umidade favorável à ação dos microrganismos.

A adoção de cultivo mínimo e a semeadura direta, associadas às culturas de cobertura, têm contribuído para a melhoria dos atributos físicos do solo (Albuquerque et al., 1995; Cattelan et al., 1997; Silva \& Mielniczuk, 1997), desde que esses manejos conservacionistas venham sendo utilizados pelo menos de três a quatro anos para o desenvolvimento de uma porosidade mais favorável ao crescimento de raízes (Albuquerque et al., 1995).

Culturas agregadoras e com sistema radicular agressivo, podem minimizar os efeitos negativos da degradação do solo por meio de melhorias na sua estrutura. Ainda são necessárias mais informações sobre quais culturas são mais apropriadas para melhorar a qualidade física do solo sob determinadas condições de solo e clima. Neste trabalho se objetivou determinar o efeito de culturas de cobertura na qualidade física de um Latossolo Vermelho distrófico de cerrado em plantio direto.

\section{MATERIAL E MÉTODOS}

O experimento foi irrigado por pivô central e conduzido na Fazenda Capivara, da Embrapa Arroz e Feijão, localizada no município de Santo Antônio de Goiás, GO, em Latossolo Vermelho distrófico. As análises química e granulométrica iniciais do solo apresentaram os seguintes resultados: $\mathrm{pH}\left(\mathrm{H}_{2} \mathrm{O}\right)$ $=5,7 ; \mathrm{Ca}^{2+}=20,5 \mathrm{mmol}_{\mathrm{c}} \mathrm{dm}^{-3} ; \mathrm{Mg}^{2+}=7,4 \mathrm{mmol}_{\mathrm{c}} \mathrm{dm}^{-3} ; \mathrm{P}=$ $21,5 \mathrm{mg} \mathrm{dm}^{-3} ; \mathrm{K}=101 \mathrm{mg} \mathrm{dm}^{-3}$; matéria orgânica $=19 \mathrm{~g} \mathrm{dm}^{-3}$, areia $=240 \mathrm{~g} \mathrm{~kg}^{-1}$; silte $=270 \mathrm{~g} \mathrm{~kg}^{-1} \mathrm{e}$ argila $=490 \mathrm{~g} \mathrm{~kg}^{-1}$. Utilizou-se o delineamento de blocos ao acaso, com oito repetições; o tamanho das parcelas foi de 3,6 m de largura por 5,0 $\mathrm{m}$ de comprimento; os tratamentos consistiram de oito culturas de cobertura: braquiária (Brachiaria brizantha $\mathrm{cv}$. Marandu); milho (Zea mays L., híbrido HT BRS 3150) consorciado 
com braquiária; guandu anão (Cajanus cajan L. Millisp); milheto (Pennisetum glaucum L. R. Br. cv. BN-2); mombaça (Panicum maximum cv. Mombaça); sorgo granífero (Sorghum bicolor L. Moench cv. BR 304); estilosantes (Stylosanthes guianensis cv. Mineirão) e crotalária (Crotalaria juncea L.). As sete primeiras culturas vêm sendo cultivadas no verão desde dezembro de 2001 e a crotalária a partir de novembro de 2003.

As culturas de cobertura foram sempre semeadas no sistema plantio direto, em novembro ou dezembro, trituradas com triturador de palha, em março ou abril, e dessecadas com glifosate (1,92 $\mathrm{kg} \mathrm{ha}^{-1}$ de i.a.) um mês após. A adubação de semeadura foi feita mecanicamente com $400 \mathrm{~kg} \mathrm{ha}^{-1} \mathrm{da}$ fórmula 5-30-5 (N- $\left.\mathrm{P}_{2} \mathrm{O}_{5}-\mathrm{K}_{2} \mathrm{O}\right)$. O consumo de sementes foi de: braquiária, mombaça e milho - $20 \mathrm{~kg} \mathrm{ha}^{-1}$; guandu - $25 \mathrm{~kg} \mathrm{ha}^{-1}$; milheto e crotalária - $40 \mathrm{~kg} \mathrm{ha}^{-1}$; sorgo - $10 \mathrm{~kg} \mathrm{ha}^{-1} \mathrm{e}$ estilosantes $-1,4 \mathrm{~kg} \mathrm{ha}^{-1}$. A semeadura do feijoeiro foi feita também sempre no sistema plantio direto, sessenta dias após a dessecação das culturas de cobertura, utilizando-se a cultivar Pérola no espaçamento de $0,45 \mathrm{~m}$, com 15 sementes por metro. A adubação foi de $400 \mathrm{~kg} \mathrm{ha}^{-1}$ da fórmula 4-30-16 + Zn no sulco e $60 \mathrm{~kg} \mathrm{ha}^{-1}$ de $\mathrm{N}$ em cobertura, na forma de uréia, aplicados: metade aos 15 dias e metade aos 25 dias após a emergência.

Em fevereiro de 2006 foram coletadas, em uma trincheira de $0,80 \times 0,80 \times 0,40 \mathrm{~m}$ por parcela, quatro amostras por profundidade estudada, 0-10 e 10-20 cm, sendo uma deformada e três não deformadas (uma no formato de torrão e duas pelo método do cilindro). A amostra com estrutura deformada foi utilizada para determinar a densidade de partículas (Dp) pelo método do balão volumétrico e o conteúdo de matéria orgânica do solo, pelo método de Walkley Black (EMBRAPA, 1997). A amostra indeformada obtida no formato de torrão foi utilizada para determinação, por via úmida, das porcentagens de agregados em classes de diâmetro médio e, com base nelas, o diâmetro médio ponderado dos agregados, segundo EMBRAPA (1997).

Uma amostra não deformada coletada em cilindro de $5 \mathrm{~cm}$ de diâmetro e $5 \mathrm{~cm}$ de altura, foi usada para determinação da densidade do solo (Ds). Calculou-se a porosidade total (Pt) pela equação: $\mathrm{Pt}=(1-\mathrm{Ds} / \mathrm{Dp})$. A microporosidade foi considerada a quantidade de água retida pelo solo na tensão de 6 $\mathrm{kPa}$. Obteve-se a macroporosidade pela diferença entre a porosidade total e a microporosidade (EMBRAPA, 1997).

A outra amostra não deformada foi usada para determinação da retenção de água do solo, pelo método da câmara de pressão de Richards (Richards \& Fireman, 1943), nas tensões de água de 6, 8, 10, 33, 60, 100 e $1500 \mathrm{kPa}$. Os dados de retenção da água foram ajustados a uma curva, por meio de regressão não-linear, utilizando-se o modelo matemático proposto por van Genuchten (1980), dado por:

$$
\theta=\left(\theta_{\text {sat }}-\theta_{\text {res }}\right)\left[1+(\alpha h)^{\mathrm{n}}\right]^{-\mathrm{m}}+\theta_{\text {res }}
$$

em que $\theta, \theta_{\text {sat }}$ e $\theta_{\text {res }}$ são, respectivamente, os conteúdos de água do solo correspondentes à tensão $\mathrm{h}$, à saturação e à umidade residual, em $\mathrm{kg} \mathrm{kg}^{-1}$; $h$ é a tensão matricial da água do solo, em $\mathrm{kPa}, n$ e $m(m=1-1 / n)$ são parâmetros empíricos adimensionais de ajuste e $\alpha$ é um parâmetro expresso em $\mathrm{kPa}^{-1}$. O ajuste foi feito com o auxílio do programa Soil Water Retention Curve - SWRC (Dourado Neto et al., 2001).

Determinou-se, com base nos parâmetros obtidos, o índice $\mathrm{S}$, tangente à curva característica de água no solo no ponto de inflexão, segundo a equação (Dexter, 2004):

$$
\mathrm{S}=-\mathrm{n}\left(\theta_{\mathrm{sat}}-\theta_{\text {res }}\right) 1+\frac{1}{\mathrm{~m}}^{-(1+\mathrm{m})}
$$

A análise de variância dos dados foi realizada por profundidade, utilizando-se o procedimento GLM do programa estatístico SAS (SAS Institute, 1999), cujas médias foram comparadas pelo teste de Tukey a 5\% de probabilidade. As médias dos tratamentos foram comparadas com as obtidas no solo de uma mata nativa (controle), situada acerca de $400 \mathrm{~m}$ do experimento, pelo teste de Dunnett a 5\%. Análises de regressão linear entre as variáveis estudadas foram realizadas considerando-se, conjuntamente, as duas profundidades de amostragem.

\section{RESULTADOS E DISCUSSÃO}

Os conteúdos de matéria orgânica foram maiores na camada superficial do solo, onde a braquiária solteira propiciou maior conteúdo que o milho consorciado com braquiária e as leguminosas guandu e estilosantes (Tabela 1). Na camada de $10-20 \mathrm{~cm}$, o solo sob braquiária apresentou maior conteúdo de matéria orgânica que o sob guandu.

Em experimento conduzido na mesma área, Stone et al. (2006) verificaram que essas leguminosas produziram as menores quantidades de matéria seca, em comparação com as demais culturas; eles notaram, também, que as maiores produções de matéria seca foram obtidas com braquiária e mombaça.

Nas duas camadas amostradas o solo sob mata apresentou maior conteúdo de matéria orgânica que os sob os de-

Tabela 1. Conteúdo de matéria orgânica do solo cultivado com diferentes culturas de cobertura, nas camadas de $0.10 \mathrm{~cm} \mathrm{e}$

\begin{tabular}{|c|c|c|}
\hline \multirow{2}{*}{ Cultura de cobertura } & \multicolumn{2}{|c|}{ Matéria orgânica $\left(\mathrm{g} \mathrm{dm}^{-3}\right)$} \\
\hline & $0-10 \mathrm{~cm}$ & $10-20 \mathrm{~cm}$ \\
\hline Braquiária & $22,8 a^{*}$ & $19,5 a^{*}$ \\
\hline Milho consorciado com braquiária & 20,9 b* & $18,1 a b *$ \\
\hline Guandu & $20,6 b^{*}$ & $18,0 b^{*}$ \\
\hline Milheto & $21,4 a b^{*}$ & $18,8 a b^{*}$ \\
\hline Mombaça & $21,9 a b *$ & $18,9 a b^{*}$ \\
\hline Sorgo & $22,0 a b *$ & $19,2 a b^{*}$ \\
\hline Estilosantes & $20,8 b^{*}$ & $18,6 a b^{*}$ \\
\hline Crotalária & $21,8 a b^{*}$ & $18,6 a b^{*}$ \\
\hline DMS & 1,8 & 1,5 \\
\hline C.V. (\%) & 5,3 & 5,0 \\
\hline Mata & 27,4 & 22,5 \\
\hline
\end{tabular}
$10-20 \mathrm{~cm}$ de profundidade ${ }^{1}$

${ }^{1}$ Médias nas colunas seguidas da mesma letra não diferem significativamente pelo teste de Tukey a $5 \%$, e as seguidas de asterisco diferem significativamente do controle, pelo teste de Dunnett a 5\% 
mais tratamentos. Solos de mata geralmente apresentam maior conteúdo de matéria orgânica que solos cultivados (Silva et al., 1998; Fonseca et al., 2007).

As culturas de cobertura afetaram, de maneira similar, a porcentagem de agregados com diâmetro maior que $2 \mathrm{~mm}$ e o diâmetro médio ponderado dos agregados (DMP) nas duas camadas amostradas, indicando que o DMP foi influenciado principalmente por esta fração dos agregados (Tabela 2).

Tabela 2. Agregados com diâmetro maior que $2 \mathrm{~mm}(>2 \mathrm{~mm}$ ) e diâmetro médio ponderado dos agregados (DMP) do solo cultivado com diferentes culturas de cobertura, nas camadas de $0-10 \mathrm{~cm}$ e $10-20 \mathrm{~cm}$ de profundidade ${ }^{1}$

\begin{tabular}{|c|c|c|c|c|}
\hline \multirow{2}{*}{ Cultura de cobertura } & \multicolumn{2}{|c|}{$>2 \mathrm{~mm}(\%)$} & \multicolumn{2}{|c|}{ DMP (mm) } \\
\hline & $0-10$ & $10-20$ & $0-10$ & $10-20$ \\
\hline Braquiária & $79,4 \mathrm{ab}$ & 66,5 a & $4,09 a b$ & $3,56 \mathrm{a}$ \\
\hline Milho consorciado com braquiária & $83,2 a^{*}$ & $75,4 a$ & $4,26 a^{*}$ & 3,93 a \\
\hline Guandu & $60,2 \mathrm{c}$ & $64,1 a^{*}$ & $3,26 \mathrm{c}$ & $3,48 a^{*}$ \\
\hline Milheto & $77,1 \mathrm{abc}$ & 69,9 a & $4,00 a b c$ & $3,72 \mathrm{a}$ \\
\hline Mombaça & $81,5 \mathrm{a}$ & 68,8 a & $4,18 \mathrm{a}$ & $3,64 a$ \\
\hline Sorgo & $74,2 a b c$ & 68,8 a & $3,89 a b c$ & $3,64 a$ \\
\hline Estilosantes & $62,60 \mathrm{bc}$ & 67,6 a & $3,37 \mathrm{bc}$ & $3,71 \mathrm{a}$ \\
\hline Crotalária & $68,8 a b c$ & 68,2 a & $3,64 a b c$ & 3,61 a \\
\hline DMS & 17,6 & 20,1 & 0,78 & 0,86 \\
\hline C.V. $(\%)$ & 15,1 & 18,5 & 12,8 & 14,8 \\
\hline Mata & 65,8 & 83,1 & 3,50 & 4,25 \\
\hline
\end{tabular}

Na camada $0-10 \mathrm{~cm}$, as coberturas de milho consorciado com braquiária e mombaça propiciaram maiores porcentagens de agregados com diâmetro maior que $2 \mathrm{~mm}$ e DMPs que as de guandu e estilosantes. Como já referido, essas duas leguminosas produziram as menores quantidades de matéria seca em comparação com as demais culturas, enquanto as maiores produções de matéria seca foram obtidas com braquiária e mombaça, cujos resultados mostram a importância das culturas na agregação do solo, especialmente gramíneas, que apresentam alta produção de matéria seca; nesta camada apenas a cobertura de milho consorciado com braquiária diferiu do controle, apresentando maiores porcentagens de agregados com diâmetro maior que $2 \mathrm{~mm}$ e DMP que a mata.

Na camada $10-20 \mathrm{~cm}$ os indicadores de agregação não diferiram entre os tratamentos, tendo a mata apresentado maiores valores desses indicadores em relação à cobertura de guandu; verifica-se, assim, que as culturas de cobertura afetaram mais a agregação da camada superficial do solo devido, possivelmente, ao maior aporte de material orgânico nessa camada.

A influência benéfica das gramíneas na estruturação e na estabilidade dos agregados do solo, tem sido demonstrada por vários pesquisadores (Tisdall \& Oades, 1979; Fassbender \& Bornemisza, 1994; Silva \& Mielniczuk, 1997), e atribuída à alta densidade de raízes, que promove a aproximação das partículas pela constante absorção de água do perfil do solo, às periódicas renovações do sistema radicular e à uniforme distribuição dos exsudatos no solo, que estimulam a ativida- de microbiana, cujos subprodutos atuam na formação e estabilização dos agregados (Silva \& Mielniczuk,1997). Tisdall \& Oades (1979) sugeriram que o aumento da estabilidade de agregados devido à ação de gramíneas, se deve à liberação de polissacarídeos por hifas de micorrizas associadas.

Apesar da tendência do DMP aumentar com o conteúdo de matéria orgânica do solo, segundo a equação $Y=2,2093+$ $0,0765 \mathrm{X}, \mathrm{r}=0,43$, este aumento não foi significativo. Wohlenberg et al. (2004), comparando cinco sistemas de sucessão de culturas, também não observaram correlação significativa entre DMP e conteúdo de carbono orgânico, mas atribuíram este fato à pequena amplitude de variação do conteúdo de carbono orgânico e à ação de outros fatores, além do carbono orgânico, como configuração de raízes, quantidade e qualidade do material orgânico sintetizado, que afetam a agregação do solo. Dufranc et al. (2004) verificaram que a comunidade bacteriana se mostrou como principal agente para a estabilização de agregados em um Latossolo Vermelho distrófico de textura franca-arenosa e um dos principais, ao lado da matéria orgânica, em um Latossolo Vermelho distrófico de textura argilosa.

O solo sob mata, por não ter sido cultivado não sofrendo os efeitos do trânsito de máquinas e equipamentos, apresentou menor valor de densidade e maiores valores de macroporosidade e porosidade total, tanto na camada superficial como na de $10-20 \mathrm{~cm}$ de profundidade, em relação ao solo sob as culturas de cobertura (Tabela 3). Normalmente, solos de mata e campo nativo apresentam maior macroporosidade, comparativamente aos solos cultivados (Albuquerque et al., 2001; Fonseca et al., 2007).

Nessas duas camadas, as diferentes coberturas do solo não diferiram em relação a esses atributos do solo, com exceção da macroporosidade na camada superficial, em que o solo sob guandu apresentou maior macroporosidade que o sob milheto. Argenton et al. (2005) verificaram que a introdução de leguminosas intercalares ao milho demonstrou ser uma prática benéfica para as propriedades relacionadas com a estrutura do solo, visto que aumentou a macroporosidade, porosidade total e reduziu a densidade do solo, quando comparada com o cultivo do milho isolado. Fonseca et al. (2007) observaram que o sistema de rotação que incluía a consorciação soja e braquiária, proporcionou menor densidade do solo e maior macroporosidade que a consorciação milho e braquiária em virtude, sem dúvida, do aumento, tanto de nitrogênio como de carbono orgânico no solo.

As coberturas não diferiram com relação à microporosidade mas na camada superficial esse atributo do solo foi menor na mata em relação às parcelas com milheto, mombaça, sorgo, estilosantes e crotalária; na camada de $10-20 \mathrm{~cm}$, o solo apresentou, sob mata, menor microporosidade que o sob milho consorciado com braquiária.

Os atributos físicos do solo foram afetados pelo conteúdo de matéria orgânica, tendo a densidade diminuído e a porosidade total e a macroporosidade aumentado com o aumento desse conteúdo no solo (Figura 1), corroborando com os resultados obtidos por Silveira Neto et al. (2006) e Juhász et al. (2007). 
Tabela 3. Densidade do solo e relações de porosidade do solo cultivado com diferentes culturas de cobertura, nas camadas de 0 - 10 $\mathrm{cm}$ e $10-20 \mathrm{~cm}$ de profundidade ${ }^{1}$

\begin{tabular}{|c|c|c|c|c|c|c|c|c|}
\hline \multirow{3}{*}{ Cultura de cobertura } & \multirow{2}{*}{$\begin{array}{l}\text { Densidade do } \\
\text { solo }\left(\mathrm{Mg} \mathrm{m}^{-3}\right)\end{array}$} & \multicolumn{3}{|c|}{ Porosidade $\left(\mathrm{m}^{3} \mathrm{~m}^{-3}\right)$} & \multirow{2}{*}{$\begin{array}{l}\text { Densidade do } \\
\text { solo }\left(\mathrm{Mg} \mathrm{m}^{-3}\right)\end{array}$} & \multicolumn{3}{|c|}{ Porosidade $\left(\mathrm{m}^{3} \mathrm{~m}^{-3}\right)$} \\
\hline & & Macro & Micro & Total & & Macro & Micro & Total \\
\hline & \multicolumn{4}{|c|}{$0.10 \mathrm{~cm}$} & \multicolumn{4}{|c|}{$10-20 \mathrm{~cm}$} \\
\hline Braquiária & 1,27 a* & $0,112 a b^{*}$ & 0,408 a & $0,520 a^{*}$ & $1,30 a^{*}$ & $0,067 a^{*}$ & $0,442 a$ & $0,510 a^{*}$ \\
\hline Milho consorciado com braquiária & $1,24 a^{*}$ & $0,157 a b^{*}$ & $0,376 a$ & $0,533 a^{*}$ & $1,33 a^{*}$ & $0,037 a^{*}$ & $0,462 a^{*}$ & $0,499 a^{*}$ \\
\hline Guandu & $1,18 a^{*}$ & $0,179 a^{*}$ & $0,374 a$ & $0,553 a^{*}$ & $1,31 a^{*}$ & $0,054 a^{*}$ & $0,453 a$ & $0,506 a^{*}$ \\
\hline Milheto & $1,32 a^{*}$ & $0,056 b^{*}$ & $0,444 a^{*}$ & $0,501 a^{*}$ & $1,33 a^{*}$ & $0,058 a^{*}$ & $0,440 a$ & $0,499 a^{*}$ \\
\hline Mombaça & $1,24 a^{*}$ & $0,121 a b^{*}$ & $0,410 a^{*}$ & $0,531 a^{*}$ & $1,32 a^{*}$ & $0,061 a^{*}$ & $0,441 \mathrm{a}$ & $0,502 a^{*}$ \\
\hline Sorgo & $1,20 a^{*}$ & $0,123 a b^{*}$ & $0,424 a^{*}$ & $0,547 a^{*}$ & $1,30 a^{*}$ & $0,081 a^{*}$ & $0,430 a$ & $0,511 a^{*}$ \\
\hline Estilosantes & $1,27 a^{*}$ & $0,106 a b^{*}$ & $0,413 a^{*}$ & $0,520 a^{*}$ & $1,39 a^{*}$ & $0,044 a^{*}$ & $0,431 a$ & $0,475 a^{*}$ \\
\hline Crotalária & $1,20 a^{*}$ & $0,122 a b *$ & $0,424 a^{*}$ & $0,545 a^{*}$ & $1,34 a^{*}$ & $0,055 a^{*}$ & $0,438 a$ & $0,492 a^{*}$ \\
\hline DMS & 0,14 & 0,112 & 0,078 & 0,053 & 0,10 & 0,054 & 0,035 & 0,040 \\
\hline C.V. (\%) & 7,1 & 57,7 & 12,0 & 6,2 & 5,0 & 60,1 & 4,9 & 5,0 \\
\hline Mata & 0,90 & 0,318 & 0,342 & 0,661 & 1,06 & 0,181 & 0,417 & 0,598 \\
\hline
\end{tabular}

${ }^{1}$ Médias nas colunas seguidas da mesma letra não diferem significativamente pelo teste de Tukey a $5 \%$, e as seguidas de asterisco diferem significativamente do controle, pelo teste de Dunnett a $5 \%$

No solo cultivado o índice $\mathrm{S}$ apresentou maiores valores na camada de $0-10 \mathrm{~cm}$ de profundidade sugerindo que a ação
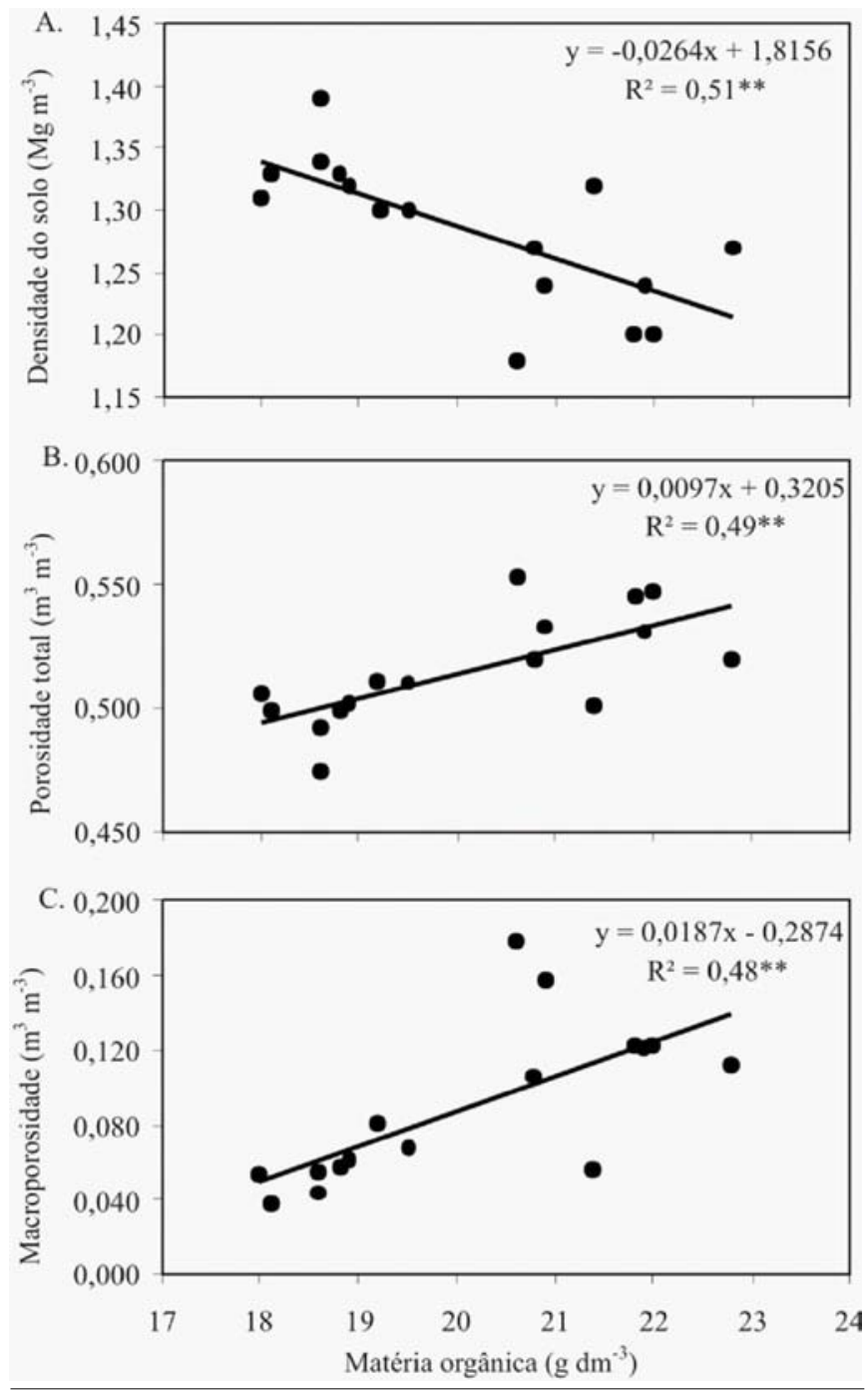

Figura 1. Atributos físicos do solo sob diferentes culturas de cobertura em função do seu conteúdo de matéria orgânica. (A) Densidade do solo; (B) porosidade total e (C) macroporosidade das coberturas na melhoria da qualidade física do solo foi mais efetiva na camada superficial (Tabela 4). As coberturas diferiram significativamente quanto a este índice mas apenas na camada de 10-20 cm, em que o solo sob cobertura de crotalária mostrou maior valor que o sob estilosantes.

Nas duas camadas amostradas o solo sob mata apresentou maior índice $\mathrm{S}$ que o sob as diferentes cobertura, indicando maior qualidade física.

Considerando o limite de $S \geq 0,045$ para solo com boa qualidade física, como determinado por Andrade (2008), apenas as coberturas de milho consorciado com braquiária, crotalária e guandu, mantiveram o solo cultivado na camada de 0 $10 \mathrm{~cm}$, nesta condição. Na camada de 10-20 cm, nenhuma cobertura contribuiu para manter o solo com tal condição estrutural.

O índice $\mathrm{S}$ está relacionado com a distribuição do tamanho de poros de maior frequiência, que é afetada pela porosidade microestrutural, isto é, poros estruturais compreendendo microfendas, fendas, bioporos e macroestruturas produzidas quando do preparo do solo (Dexter, 2004); assim,

Tabela 4. Índice $S$ sob diferentes culturas de cobertura, nas camadas de $0-10 \mathrm{~cm}$ e $10-20 \mathrm{~cm}$ de profundidade ${ }^{1}$

\begin{tabular}{ccc}
\hline \multirow{2}{*}{ Cultura de cobertura } & \multicolumn{2}{c}{ Índice $\mathbf{~}$} \\
\cline { 2 - 3 } Braquiária & $\mathbf{0 - 1 0} \mathbf{~ c m}$ & $\mathbf{1 0 - 2 0} \mathbf{c m}$ \\
Milho consorciado com braquiária & $0,040 \mathrm{a}^{*}$ & $0,032 \mathrm{ab} *$ \\
Guandu & $0,045 \mathrm{a}^{*}$ & $0,025 \mathrm{ab} *$ \\
Milheto & $0,058 \mathrm{a}^{*}$ & $0,027 \mathrm{ab} *$ \\
Mombaça & $0,034 \mathrm{a}^{*}$ & $0,024 \mathrm{ab} *$ \\
Sorgo & $0,042 \mathrm{a}^{*}$ & $0,031 \mathrm{ab} *$ \\
Estilosantes & $0,042 \mathrm{a}^{*}$ & $0,028 \mathrm{ab} *$ \\
Crotalária & $0,042 \mathrm{a}^{*}$ & $0,019 \mathrm{~b}^{*}$ \\
DMS & $0,057 \mathrm{a}^{*}$ & $0,036 \mathrm{a}^{*}$ \\
C.V. (\%) & 0,030 & 0,015 \\
Mata & 41,8 & 33,9 \\
\hline
\end{tabular}

${ }^{1}$ Médias nas colunas seguidas da mesma letra não diferem significativamente pelo teste de Tukey a $5 \%$, e as seguidas de asterisco diferem significativamente do controle, pelo teste de Dunnett a 5\% 

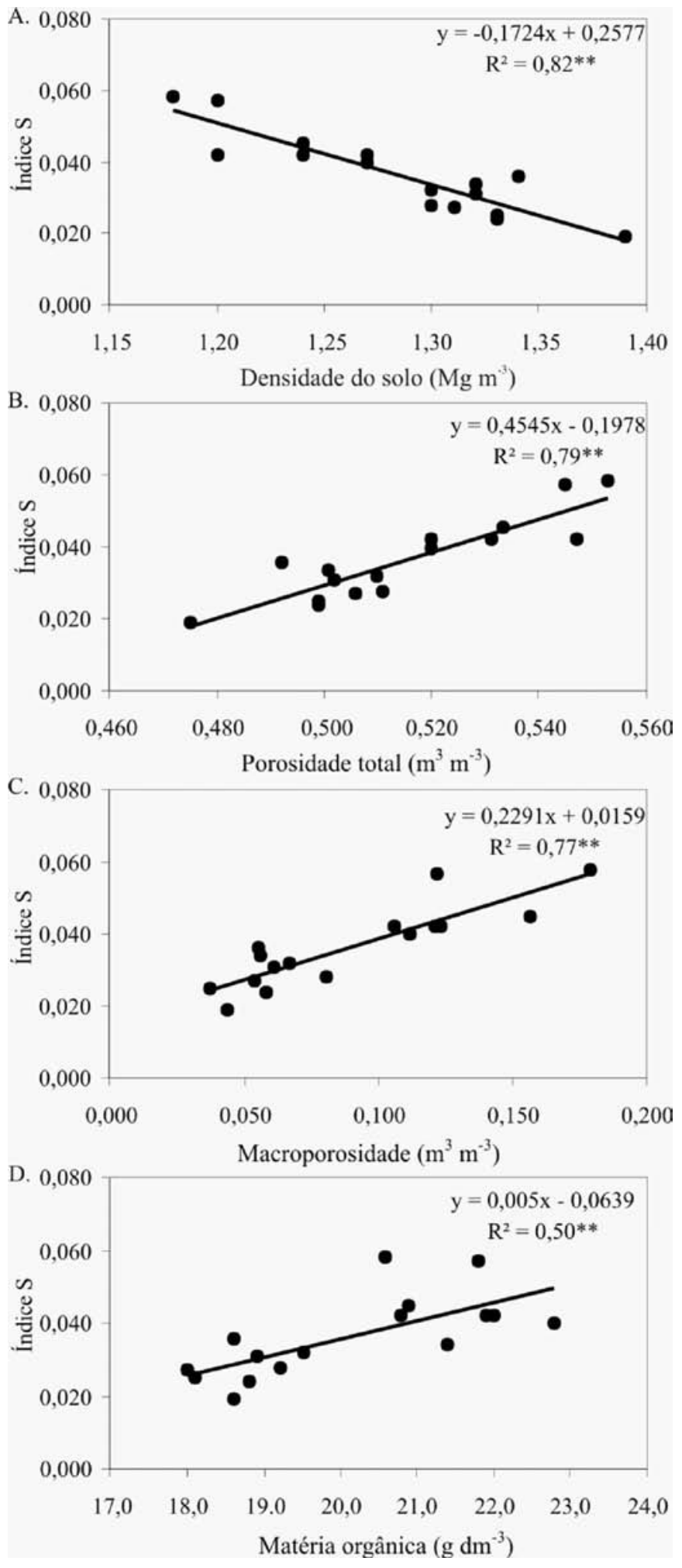

Figura 2. Índice $S$ sob diferentes culturas de cobertura, em função de $(A)$ densidade do solo, (B) porosidade total, (C) macroporosidade e (D) matéria orgânica do solo

no SPD as plantas de cobertura afetam favoravelmente este índice, ao criarem poros biológicos de alta funcionalidade na aeração e infiltração de água no solo. Como reflexo desta funcionalidade, Genro Júnior (2002) observou, em solo argiloso, tendência de aumento da condutividade hidráulica saturada após a inclusão de guandu anão em esquemas de rotação de culturas com milho, soja e trigo. Abreu et al. (2004) atribuíram o aumento da condutividade hidráulica saturada do solo sob crotalária em relação ao solo descoberto e à soja em plantio direto ou em solo escarificado, à formação e à manutenção de macroporos verticais ao longo do perfil do solo, decorrentes da decomposição das raízes, e à agressividade do sistema radicular da crotalária, penetrando a camada subsuperficial do solo e constituindo um meio poroso mais contínuo. Com relação às gramíneas, Salton et al. (1999) verificaram maior permeabilidade do solo em áreas nas quais a soja teve pastagem como cultura antecedente.

Observa-se que a qualidade física do solo, avaliada pelo índice $\mathrm{S}$, está inversamente relacionada com a densidade do solo (Figura 2A) e diretamente relacionada com o seu espaço poroso (Figuras 2B e 2C), corroborando com os resultados obtidos por Stone et al. (2005) e Juhász et al. (2007). Verificase, também, a importância do conteúdo de matéria orgânica do solo nesse índice (Figura 2d), tal como observado também por Juhász et al. (2007).

As coberturas de milho consorciado com braquiária, crotalária e guandu estão, em valor absoluto, entre as que propiciaram maiores valores de macroporosidade e menores de densidade do solo, explicando os maiores valores de índice $\mathrm{S}$ sob essas coberturas.

$\mathrm{O}$ índice $\mathrm{S}$ não se correlacionou significativamente com o DMP $\left(\mathrm{R}^{2}=0,003^{\mathrm{ns}}\right)$, possivelmente pelo fato do DMP não avaliar a qualidade estrutural do solo quanto à distribuição do tamanho de poros (Forsythe, 1975); desta forma, poros demasiadamente grandes, formados por macroagregados, não conseguem reter água e, por isso, não aparecem na curva de retenção de água não contribuindo, portanto, para o valor do índice S (Dexter, 2004).

\section{CONCLUSÕES}

1. As culturas de cobertura, especialmente as gramíneas, favoreceram a agregação do solo na camada superficial, mantendo-a ou a aumentando em relação à apresentada pelo solo sob mata nativa.

2. O cultivo do solo, mesmo em plantio direto e com a utilização de culturas de cobertura, modificou a sua estrutura comparativamente à condição original com mata nativa, aumentando a densidade e reduzindo a macroporosidade, porosidade total e qualidade física do solo.

3 . Os atributos físicos do solo foram afetados favoravelmente pelo seu conteúdo de matéria orgânica, tendo o cultivo do solo reduzido esse conteúdo em relação à mata nativa.

4. O índice $\mathrm{S}$ correlacionou-se com os atributos físicos do solo e com o seu conteúdo de matéria orgânica, mostrando-se adequado como indicador da qualidade física do solo.

5. Entre as culturas de cobertura estudadas, as leguminosas guandu e crotalária, e o milho consorciado com braquiária, foram as que mantiveram a camada superficial do solo cultivado com boa qualidade física. 


\section{LITERATURA CITADA}

Abreu, S. L.; Reichert, J. M.; Reinert, D. J. Escarificação mecânica e biológica para a redução da compactação em Argissolo franco-arenoso sob plantio direto. Revista Brasileira de Ciência do Solo, v.28, n.3, p.519-531, 2004.

Albuquerque, J. A.; Reinert, D. J.; Fiorin, J. E.; Ruedell, J.; Petrere, C.; Fontinelli, F. Rotação de culturas e sistemas de manejo do solo: Efeito sobre a forma da estrutura do solo ao final de sete anos. Revista Brasileira de Ciência do Solo, v.19, n.1, p.115-119, 1995.

Albuquerque, J. A.; Sangoi, L.; Ender, M. Efeitos da integração lavoura-pecuária nas propriedades físicas do solo e características da cultura do milho. Revista Brasileira de Ciência do Solo, v.25, n.3, p.717-723, 2001.

Amado, T. J. C.; Bayer, C.; Eltz, F. L. F.; Brum, A. C. R. Potencial de culturas de cobertura em acumular carbono e nitrogênio no solo no plantio direto e a melhoria da qualidade ambiental. Revista Brasileira de Ciência do Solo, v.25, n.1, p.189-197, 2001.

Andrade, R da S. Efeito de culturas de cobertura na qualidade física do solo sob plantio direto. Goiânia: UFG, 2008. 78p. Tese Doutorado

Argenton, J.; Albuquerque, J. A.; Bayer, C.; Wildner, L. do P. Comportamento de atributos relacionados com a forma da estrutura de Latossolo Vermelho sob sistemas de preparo e plantas de cobertura. Revista Brasileira de Ciência do Solo, v.29, n.3, p.425-435, 2005.

Bayer, C.; Mielniczuk, J. Nitrogênio total de um solo submetido a diferentes métodos de preparo e sistemas de cultura. Revista Brasileira de Ciência do Solo, v.21, n.2, p.235-239, 1997.

Bayer, C.; Mielniczuk, J.; Martin-Neto, L. Efeito de sistemas de preparo e de cultura na dinâmica da matéria orgânica e na mitigação das emissões de $\mathrm{CO}_{2}$. Revista Brasileira de Ciência do Solo, v.24, n.3, p.599-607, 2000.

Campos, B. C.; Reinert, D. J.; Nicolodi, R.; Cassol, L. C. Dinâmica da agregação induzida pelo uso de plantas de inverno para cobertura do solo. Revista Brasileira de Ciência do Solo, v.23, n.2, p.386-391, 1999.

Cattelan, A. J.; Gaudêncio, C. A.; Silva, T. A. Sistemas de rotação de culturas em plantio direto e os organismos do solo, na cultura da soja, em Londrina. Revista Brasileira de Ciência do Solo, v.21, n.2, p.293-301, 1997.

Corazza, E. J.; Silva, J. E.; Resck, D.V.S.; Gomes, A.C. Comportamento de diferentes sistemas de manejo como fonte ou depósito de carbono em relação à vegetação de cerrado. Revista Brasileira de Ciência do Solo, v.23, n.2, p.425-432, 1999.

Dao, T.H. Tillage system and crop residue effects on surface compaction of a paleustoll. Agronomy Journal, v.88, n.2, p.141-148, 1996.

Dexter, A.R. Soil physical quality. Part I. Theory, effects of soil texture, density, and organic matter, and effects on root growth. Geoderma, v.120, n.3, p.201-214, 2004.

Dourado Neto, D.; Nielsen, D. R.; Hopmans, J. W.; Reichardt, K.; Bacchi, O. O. S.; Lopes, P.P. Programa para confecção da curva de retenção de água no solo, modelo Van Genuchten. Soil Water Retention Curve, SWRC (version 3,00 beta). Piracicaba: Universidade de São Paulo, 2001.
Dufranc, G.; Dechen, S. C. F.; Freitas, S. S.; Camargo, O. A. Atributos físicos, químicos e biológicos relacionados com a estabilidade de agregados de dois latossolos em plantio direto no Estado de São Paulo. Revista Brasileira de Ciência do Solo, v.28, n.3, p.505-517, 2004.

EMBRAPA - Empresa Brasileira de Pesquisa Agropecuária. Centro Nacional de Pesquisa de Solos. Manual de métodos de análise de solos. 2.ed. Rio de Janeiro: Embrapa-CNPS, 1997. 212p. Documentos, 1.

Fassbender, H. W.; Bornemisza, E. Química de suelos: Com énfasis en suelos de América Latina. 2.ed. San José: IICA, 1994. 420p.

Fonseca, G. C.; Carneiro, M. A. C.; Costa, A. R. da; Oliveira, G. C. de; Balbino, L. C. Atributos físicos, químicos e biológicos de Latossolo Vermelho distrófico de cerrado sob duas rotações de cultura. Pesquisa Agropecuária Tropical, v.37, n.1, p.22-30, 2007.

Forsythe, W. Física de suelos: Manual de laboratório. New York: University Press, 1975. 324p.

Genro Júnior, S. A. Alteração da compactação do solo com o uso de rotação de culturas no sistema plantio direto. Santa Maria: UFSM, 2002. 90p. Dissertação Mestrado

Hargrove, W. L. Winter legumes as a nitrogen source for no-till grain sorghum. Agronomy Journal, v.78, n.1, p.70-74, 1986.

Haynes, R. J.; Beare, M. H. Influence of six crop species on aggregate stability and labile organic matter fractions. Soil Biology \& Biochemistry, v.29, n.11, p.1647-1653, 1997.

Juhász, C. E. P.; Cooper, M.; Cursi, P. R.; Ketzer, A. O.; Toma, R. S. Savanna woodland soil micromorphology related to water retention. Scientia Agricola, v.64, n.4, p.344-354, 2007.

Primavesi, A. O manejo ecológico do solo. 4.ed. São Paulo: Nobel, 1982. 541p.

Reid, J. B.; Goss, M. J. Interactions between soil drying due to plant water use and decreases in aggregate stability caused by maize roots. Journal of Soil Science, v.33, n.1, p.47-53, 1982.

Richards, L. A.; Fireman, M. Pressure plate apparatus for measuring moisture sorption and transmission by soils. Soil Science, v.56, p.395-404, 1943.

Salton, J. C.; Hernani, L. C.; Broch, D. L.; Fabrício, A. C. Alterações em atributos físicos do solo decorrentes da rotação soja-pastagem, no Sistema Plantio Direto. Dourados: Embrapa Agropecuária Oeste, 1999. 5p. Comunicado Técnico, 10

SAS Institute Inc. SAS/STAT procedure guide for personal computers: version 5. Cary, 1999.

Silva, I. de F.; Mielniczuk, J. Ação do sistema radicular de plantas na formação e estabilização de agregados do solo. Revista Brasileira de Ciência do Solo, v.21, n.1, p.113-117, 1997.

Silva, M. L. N.; Blancaneaux, P.; Curi, N.; Lima, J. M.; Marques, J. J. G. S. M.; Carvalho, A. M. Estabilidade e resistência de agregados de um Latossolo Vermelho-Escuro cultivado com sucessão milho-adubo verde. Pesquisa Agropecuária Brasileira, v.33, p.97-103, 1998.

Silveira Neto, A. N. de; Silveira, P. M. da; Stone, L. F.; Oliveira, L. F. C. de. Efeitos de manejos e rotação de culturas em atributos físicos do solo. Pesquisa Agropecuária Tropical, v.36, n.1, p.29-35, 2006.

Stone, L. F.; Balbino, L. C.; Cunha, E. Q. Índice S como indicador da qualidade física do solo. In: Congresso Brasileiro de Engenharia Agrícola, 34, 2005, Canoas. Resumos... Canoas: Universidade Luterana do Brasil, 2005. CD-Rom. 
Stone, L. F.; Silveira, P. M. da; Moreira, J. A. A.; Braz, A. J. B. P. Evapotranspiração do feijoeiro irrigado cultivado em plantio direto sobre diferentes palhadas de culturas de cobertura. Pesquisa Agropecuária Brasileira, v.41, n.4, p.577-582, 2006.

Tisdall, J. M.; Oades, J. M. Stabilization of soil aggregates by the root systems of ryegrass. Australian Journal of Soil Research, v.17, p.429-441, 1979. van Genuchten, M. T. A closed-form equation for predicting the hydraulic conductivity of unsaturated soils. Soil Science Society of America Journal, v.44, p.892-898, 1980.

Wohlenberg, E.V.; Reichert, J.M.; Reinert, D.J.; Blume, E. Dinâmica da agregação de um solo franco-arenoso em cinco sistemas de culturas em rotação e em sucessão. Revista Brasileira de Ciência do Solo, v.28, n.5, p.891-900, 2004. 